\title{
Planning and Teaching design thinking online
}

\author{
Dr.Kalyana Chakravarthy Chilukuri ${ }^{1}$ \\ ${ }^{1}$ Computer Science and Engineering, MVGR College of Engineering (Autonomous), Vizianagaram \\ ${ }^{1}$ kalyan@mvgrce.edu.in
}

\begin{abstract}
Although design thinking for innovation has been in practice for a long time, design thinking for social entrepreneurship is gaining immense popularity in recent years. The rapid advancements in technology have been a contributor to such demand. There is considerable literature related to design thinking available through resources online. However most of it focuses on conducting the course in an offline mode. Although online student engagement has considerably improved due to the prevailing pandemic, conducting group based activities nevertheless remains a challenge to any teacher. Traditional classroom learning fosters creative engagement by teamwork. However, in an online setup, promoting an entrepreneurial mindset is a different ball game. It would require a huge effort on the part of a teacher to bring collaboration and innovation on board, given the resources and different mindsets of learners. Efforts in planning and delivering a design thinking course online, incorporating team building strategies and online tools for delivery and assessment are highlighted in this work. The course is conducted on MS Teams and is offered to semester three under graduate students across all disciplines as a part of our curriculum. Tools like slack, Trello are used for collaboration and communication. Happiness-Index (HI) metrics are developed to continuously measure the efficacy of the proposed methodology and the Anti-Air Teamwork Observation Measure (ATOM) model is used to measure the overall ratings of the team's performance, the obvious outcome of the method being how seamlessly it leads to innovations.
\end{abstract}

Keywords: Design thinking, entrepreneurial mindset, tools, Happiness-index, ATOM

\section{Introduction}

Design thinking is essential in every walk of our life. It can be used to solve as simple a problem as deciding the daily routine of life, to tackling much larger wicked societal problems such as those related to the environmental, political, financial issues, in addition to product development and innovation. Recently design thinking is finding wide application in business modelling for entrepreneurship and social network analysis. Of the different frameworks for Design thinking, the one by the IDEO and the Stanford's DSchool stand out and are used extensively by Designers. Design thinking is about getting into the mindset of Designers and thinking as they do, and requires certain basic skills. Design thinking, by definition, involves in a systematic human-centred approach for collaboratively solving problems leading to innovation. In the traditional classroom environment, students could be divided into teams and motivated to identify problems suitable for Design. Primary challenges are to teach them empathy, while at the same time, being decisive at various points in the process. For example issues such as which ideas are the best ones to choose during brainstorming might create a divide in opinion or individual differences in certain cases. The role of the teacher is different from traditional mentoring to a facilitator and the involvement should be minimal to promote independent thinking in students. This might sometimes be construed as lack of enthusiasm and participation of faculty by the students. The biggest challenge of course is to ensure participation of all students in a team. In a workshop environment, the participants are limited and focus is confined to product design or a similar activity for a limited amount of time. The teacher will have the flexibility to move around, monitor the students and observe how they are progressing. The online environment is a different proposition. Teaching design thinking and product innovation to larger groups by a single teacher online is a daunting task. Throughout the course the teacher needs to track the participation, progress, keep the students enthralled and active. The objective of the course should be to 'make believe' right from the start. The course would start with brushing up the basic drawing and analytical skills and progress to the much needed interviewing, story boarding, prototyping skills of students. Building right teams is extremely important for the success of design thinking and innovation, since quality outcome can be achieved by quality teams. Our paper focuses on an effective team building strategy, online tools for collaboration and finally the much needed assessment mechanism for the course based on both instructor and the peer reviews.

\section{Literature review}

Design thinking consists of the phases empathize, define, ideate, prototype and test. Design thinking as a creative approach for problem solving has been described in (Foster, and Mary, 2019) where the activities were conducted by three doctoral candidates as a workshop at a school event. The entire activities from introduction, forming teams, identifying challenge, solving the challenge, discussing outcomes, and problem solving approaches were completed in less than two and a half hours. The team building was done by grouping into majors or by the instructor proposing some topics and students forming affinity groups by interest. However in a true sense, design thinking will need students to identify the challenges by themselves. There has been considerable number of tools proposed related to design thinking. (Chasanidou D et al., 2015) proposed 
tools like Smaply Touch point dashboard, Business Model Canvas, Axure RP. The authors introduced participants who had prior experience with pen and paper workshops to online tools in two hour workshops using the Smaply tool and found the participation quite satisfactory. However, this tool is for evaluation for a limited period only. Further several blogs explain how to conduct short design sprints and suggest tools for design thinking that are mostly commercial or complex to use (https://www.innovationtraining.org/software-tools-fordesignthinking,2020),(https://www.invisionapp.com/insidedesign/design-thinking-tools,2020). Further most of these serve as refresher or foundation courses at high school level. The course introduced on full scale in a technical education such an Engineering school will tremendously boost the quality of projects and the higher order thinking skills of students. With this objective on mind, we have introduced Design Thinking and Product Innovation in the third semester of our Engineering curriculum that imparts knowledge of all three aspects - product development and innovation, design thinking to undergraduate students. This is essential, as students of different disciplines get to think and work together. For instance, a student of Computer Science and Engineering will not otherwise have any idea of product development while a student of Mechanical Engineering does have a separate course on production engineering. Similarly, a student of Mechanical Engineering, otherwise, will not get to know software development models such as the Agile framework widely used in the software industry today. While conducting the course offline is a challenge in itself, it needs to be conducted completely in an online mode due to the prevailing pandemic. This work attempts to address most of these challenges and provides a framework to conduct the course successfully online.

\section{The proposed framework}

The Economic Co-operation and Development (OECD) measures of quality of life were identified through eleven

\section{Dr.Kalyana Chakravarthy Chilukuri \\ Professor, Department of CSE, MVGR College of engineering(Autonomous), Vizianagaram \\ kalyan@ mvgrce.edu.in}

criteria, viz., housing, jobs, education, civic engagement, life satisfaction, work-life balance, income, community, environment, health, and safety(Shanahan, C. et al, 2007).

The QOL could be measured by nine indicators in the order of importance 1) material welfare (according to GNP) 2) health 3) political stability and safety 4) family life 5) social life 6) climate and geographical location 7) employment 8) political freedom 9) gender freedom. The Mercer Human Research uses the seven similar criteria to determine QOL.

QOL - quality of life value

$\mathrm{Si}$ - self-improvement value

$\mathrm{Sph}$ - physical state value $\mathrm{Sl}$ - self-expression and leisure value
$\mathrm{Sm}$ - material state value Sse - safety and environment

value

$\mathrm{Se}$ - emotional state value

Ss - social relationship

Sa- Abductive thinking skill

Note the numbers indicate QOL weights (sum total is 1).

Where QOL $=0,3 * \mathrm{Sph}+0,18 * \mathrm{Sm}+0,2 * \mathrm{Se}+0,1 * \mathrm{Ss}+$ $0,12 * \mathrm{Si}+0,05 * \mathrm{~S} 1+0,05 * \mathrm{Sse}(1)$.

Since thinking is related to the state of wellbeing, we believe that the Quality of Life in turn effects the quality of thinking and innovation.

We propose a Quality of Thinking (QoT) metric as

$\mathrm{QoT}=0,2 * \mathrm{Sph}+0,2 * \mathrm{Se}+0,1 \mathrm{Sm}+0,1 * \mathrm{Sl}+0,1 * \mathrm{Ss}+$ $0,12 * \mathrm{Sa}+0,18 * \mathrm{Si}$

The Physical state and emotional state values are extremely important followed by the material state value. Since Design thinking requires a flexibility and constant thriving for improvement, the self-improvement value comes next in our new ranking.

Social relationship and self-expression are equally important, in our new metric. This is because, even if a candidate is very good at expressing him/her self, unless they are well connected socially, their knowledge may not add value to the team. On the other hand a student who is very sociable but lacks self-expression may not contribute either.

Also, the material state value used here is in different context. It is believed that students who come from a moderate financial background and standard of living would be able to understand social problems better than those who come from affluent families.

A survey is conducted with the respective counsellors to grade the student on these attributes on a 10 point scale. Students are then merged into teams of three according to their QoT values by combining them according to the distribution illustrated below.

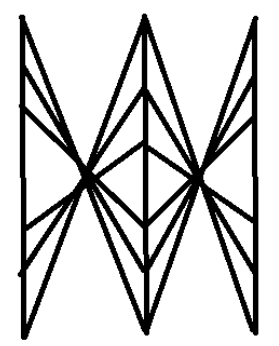

Group 1 Group 2 Group 3

Fig. 1 Combining students of different levels measured by QoT

Such a distribution would ensure a proper and fair distribution of candidates by their thinking capabilities. This is different from the regular way of combining students purely by their grades. In fact, here we don't consider only the grades of students, since quite often, it is an average student who would be a better thinker and innovator in a right environment. However, students are evaluated for their abductive reasoning skills indicated by the Sa metric using a short quiz, as design thinking predominantly uses abductive thinking.

Having built the teams, the next step is to choose the tools to conduct the course online. The chat feature in MSTeams that records the conversations and posts them on the 
channel to be available even after the meeting is extremely useful to track the participation. Teachers would pause every now and then and ask students to think about and post what they think could be possible choices. Since Design thinking is highly subjective, everyone is entitled to their perspective and all ideas should be welcome. Another way to track student participation is by both subjective and objective questions using the Microsoft Forms .

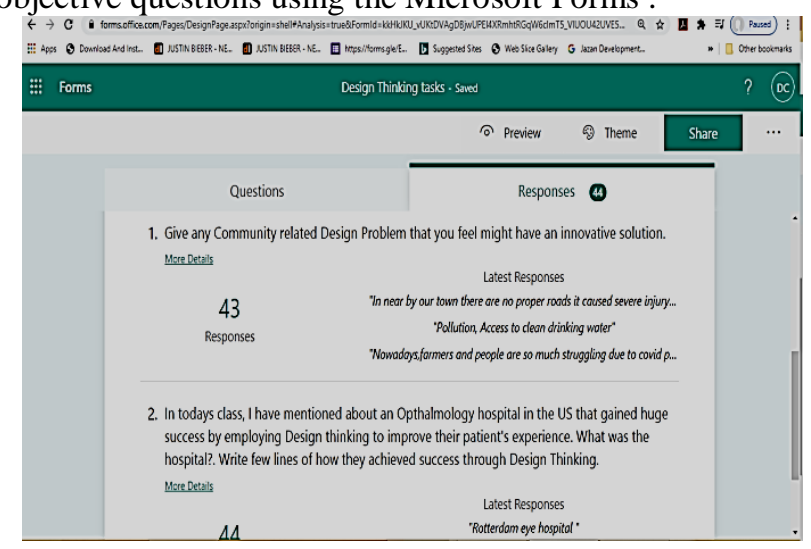

Fig. 2 Microsoft forms for subjective and objective questions

The drawchat is an excellent free tool for online collaboration and storyboarding. It allows students to seemlessly storyboard draw and share their work instantly using a chat link. The receiver can then open the link directly add anything to the drawing and send back to their team with comments.

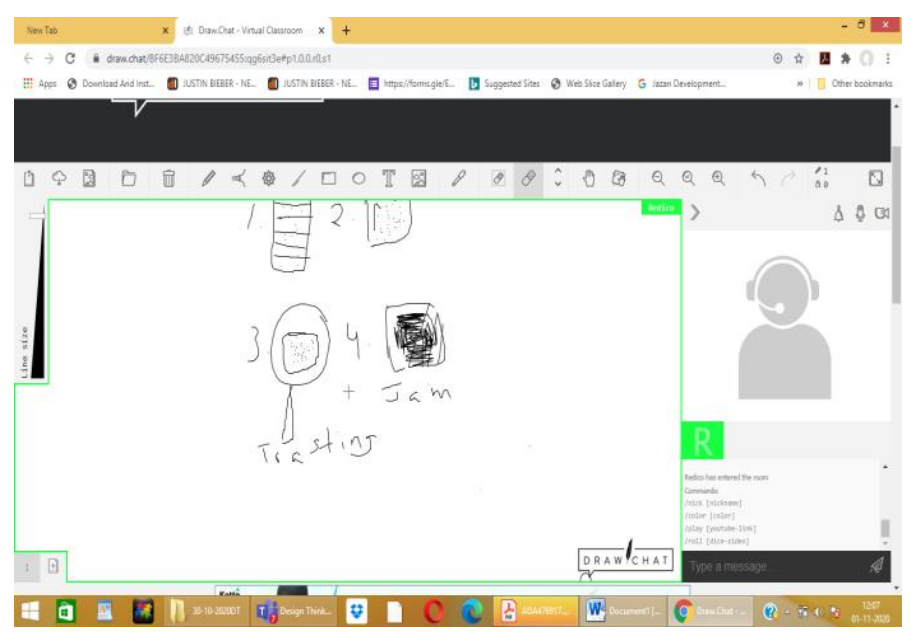

Fig. 3 DrawChat for storyboarding

Slack is another tool that make organizing teams extremely easy through channels. The @ tag allows to directly address and send messages to members of a team. Students can set reminders for themselves, upload files and pictures and can collaborate dynamically and seamlessly.

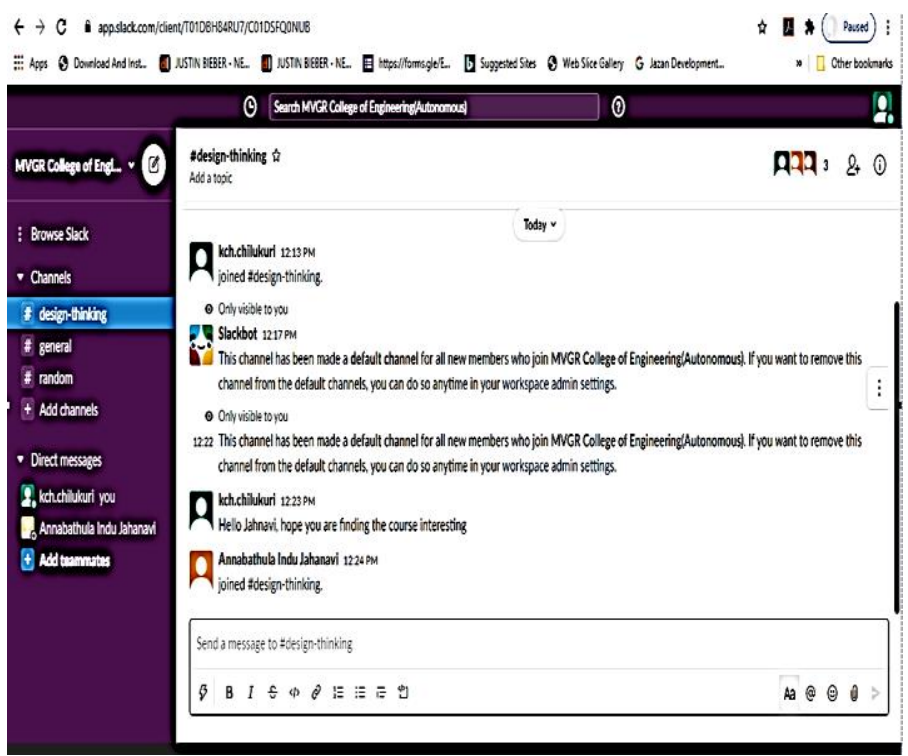

Fig. 4 The Slack tool for team collaborations

Trello is yet another power tool for collaboration online. It allows users to share tasks between teams in the form of cards that could be added to a board and personalized. For brain storming and idea generation, the tricider tool is used. It allows rapid idea generation and voting for these ideas within a specified time frame. The xoyondo tool is used for anonymous dot voting and for selection of ideas. Since assessment is subjective rather than objective, the Anti-Air Teamwork Observation Measure (ATOM) that includes the four measures Communication Behaviour Rating was used. Improper Phraseology 0 1-3 >3

Inaudible Communication 0 1-3>3

Excess Chatter 0 1-3>3

Incomplete Reports 0 1-3>3 is used.

The model helps in identifying any problems early and taking corrective actions. The frequency of behaviour is measured, whether 0 times, 1 to 3 times or more than three times and suitable corrections are made. However, rather than the instructor do the grading, it is left to the peer teams to anonymously grade every other team using the above method.

The following assessment form with twelve questions such as -

- Team members understand goals and objectives clearly, and they are committed to them.

- Everyone participates and is heard in group discussions.

- Team members are accountable for their results and meet deadlines.

- The team demonstrates effective decision making. etc., are used not only to measure the above behaviours but also the openness, honesty, conflict resolution, leadership, decision making etc., is used by the instructor. 


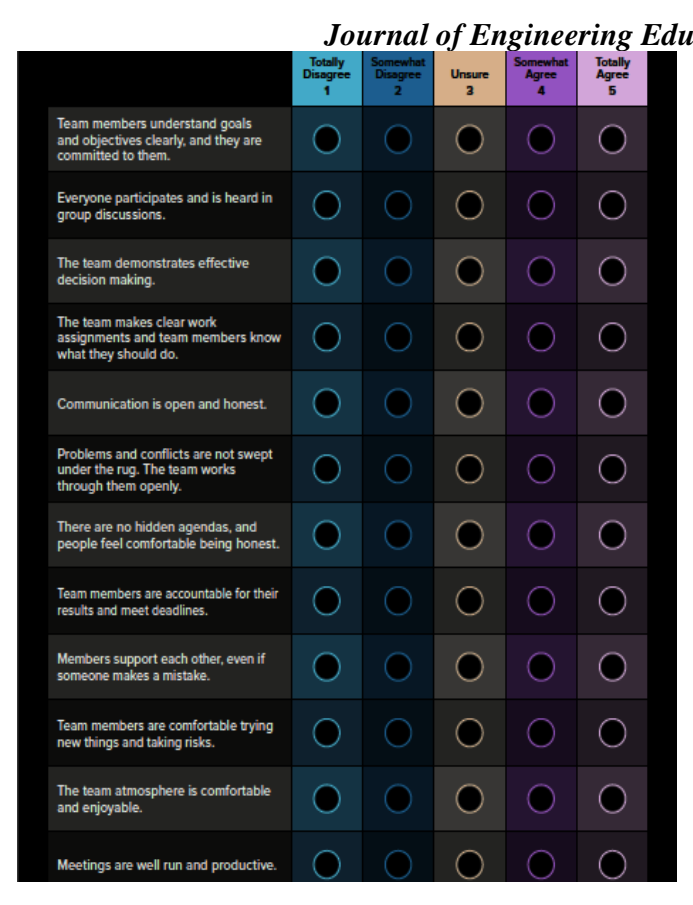

Fig. 5 Student assessment form

Both the assessments are continuous and are conducted for all the teams. Individual assessment is based on short quizzes, student response and participation through chats and discussions and submission of individual activities such as storyboarding and idea sharing. The internal evaluation is continuous and is for $50 \%$. The $50 \%$ for external evaluation includes knowledge level, analytical level and application level questions.

\section{Results}

For the purpose of results, we have considered the the mean of assessment scores of eight groups of students drawn randomly from 24 groups, each group having three students, using the regular team formation and instruction strategy (without design tools) vs assessment scores after the proposed team formation and design tools were employed. The t-test is used to determine if the difference of means are significant.

Table 1.Assessment scores for the assessment form items Regular vs proposed method

\begin{tabular}{|c|c|c|}
\hline \multicolumn{3}{|c|}{ proposed method } \\
\hline Assessment criteria & regular & proposed \\
\hline 1 & 3 & 4 \\
\hline 2 & 2 & 4 \\
\hline 3 & 2 & 3 \\
\hline 4 & 2 & 4 \\
\hline 5 & 3 & 4 \\
\hline 6 & 2 & 4 \\
\hline 7 & 2 & 4 \\
\hline 8 & 3 & 5 \\
\hline 9 & 3 & 4 \\
\hline 10 & 3 & 4 \\
\hline 11 & 3 & 5 \\
\hline 12 & 2 & 4 \\
\hline
\end{tabular}

The t-score for the samples is calculated as:

$$
\mathrm{t}=\frac{\left(\sum \mathrm{D}\right) / \mathrm{N}}{\sqrt{\frac{\sum \mathrm{D}^{2}-\left(\frac{\left(\sum D\right)^{2}}{\mathrm{~N}}\right)}{(N-1)(N)}}}
$$

Where $\Sigma \mathrm{D}$ : Sum of the differences (Sum of X-Y)

$$
\Sigma \mathrm{D}^{2}: \text { Sum of the squared differences }
$$

$(\Sigma \mathrm{D})^{2}$ : Sum of the differences squared.

For the above sample, with a significance level of 0.05 , the $\mathrm{t}$-score obtained for a two-tailed distribution was 10.65.

The degrees of freedom is samplesize- $1=12-1=11$.

The p-value was observed to be less than significance level i.e, 0.05. So the hypothesis that there is no significant difference between means can be rejected. Further, the result is significant at $\mathrm{p}<0.05$. Results show that our proposed method of team formation and instruction delivery using design tools have yielded significantly satisfactory results in terms of assessment scores when compared to the normal method of team formation and instruction without using online design tools.

\section{Conclusions}

We propose a framework to implement design thinking online. The team building and assessment strategies are unique and the tools used for instruction are simple and available for effective collaboration. While the assessment scores have shown improvement for eight randomly sampled groups with the proposed strategy, the effectiveness of the strategy shall be confirmed over the groups by counting the number of innovations in these groups with and without the proposed strategies. This shall be carried out as an extension, as we are still in the assessment phase. A consistent number of quality innovations across randomly sampled groups would mean that the proposed framework is successful. The threshold is set to $40 \%$ which means there should be at least three quality innovations in eight groups as a rubric for course outcome attainment.

\section{References}

Foster, Mary. (2019). Design Thinking: A Creative Approach to Problem Solving. Management Teaching Review. 237929811987146. 10.1177/2379298119871468.

Chasanidou D., Gasparini A.A., Lee E. (2015) Design Thinking Methods and Tools for Innovation. In: Marcus A. (eds) Design, User Experience, and Usability: Design Discourse. Lecture Notes in Computer Science, vol 9186. Springer, Cham. https://doi.org/10.1007/978-3-31920886-2_2

https://www.worldschool.nl/hugs/werkstukkek20162017/2\%20Selin\%20Beijersbergen\%20and\%20Shirley $\% 20$ de\%20Wit.pdf, 2015, Selin Beijersbergen and Shirley de Wit , Happiness -Worldschool

https://www.innovationtraining.org/software-tools-fordesign-thinking/, 10/30/2020

https://www.invisionapp.com/inside-design/designthinking-tools/, 10/30/2020

Shanahan, C. et al. "Measurement of the Behavioural, Cognitive, and Motivational Factors Underlying Team Performance.” (2007). 